\title{
Preconcentration of Heavy Metal Ions Using Synergistic Extraction with Dithizone and Tributylphosphine Oxide on the Basis of HSAB Rule
}

\author{
Hiroshi Kawamoto, Satoshi Yamazaki, Eiji Katoh, Kin-ichi Tsunoda and Hideo Akaiwa \\ Department of Applied Chemistry, Faculty of Engineering, Gunma University, Kiryu 376, Japan
}

Keywords Heavy metal ion, preconcentration, HSAB rule, inductively coupled plasma atomic emission spectrometry

Synergistic extraction with a mixture of dithizone and tributylphosphine oxide (TBPO) has been applied to the preconcentration of $\mathrm{Co}^{\mathrm{II}}$ and $\mathrm{Cd}^{\mathrm{II}}$ in river waters. ${ }^{1,2}$ Chelate extraction constants $\left(K_{\mathrm{ex}}\right)$ could be rationalized by HSAB (hard and soft acids and bases) rule ${ }^{3}$, into which a new dual parameter scale for strength $\left(S_{\mathrm{A}}\right)$ and soft $\left(\sigma_{\mathrm{A}}\right)$ factors of a metal ion $\left(\mathrm{M}^{z^{+}}\right)$was introduced: ${ }^{4}$

$$
\log K_{\mathrm{ex}}+z \mathrm{p} K_{\mathrm{a}}=S_{\mathrm{A}} S_{\mathrm{B}}+\sigma_{\mathrm{A}} \sigma_{\mathrm{B}}
$$

where the subscripts A and B denote Lewis acid and base, and $\mathrm{p} K_{\mathrm{a}}$ is the acid dissociation exponent of a chelating agent. In this work, a method for simultaneous preconcentration of $\mathrm{Cd}^{\mathrm{II}}, \mathrm{Co}^{\mathrm{II}}, \mathrm{Cu}^{\mathrm{II}}, \mathrm{Ni}^{\mathrm{II}}, \mathrm{Pb}^{\mathrm{II}}$ and $\mathrm{Zn}^{\mathrm{II}}$ using dithizone extraction was designed based on the HSAB rule, and was applied to inductively coupled plasma atomic emission spectrometry (ICP-AES).

\section{Experimental}

\section{Apparatus}

A Shimadzu Model ICPS-1000III ICP atomic emission spectrometer equipped with a plasma torch for organic solvent was used. The operating conditions of the spectrometer are summarized in Table 1. A Horiba Model F- 80 pH analyzer and an Iwaki KM type shaker were used for $\mathrm{pH}$ measurements and shaking of separatory funnels, respectively.

Table 1 Operating conditions of the ICP spectrometer

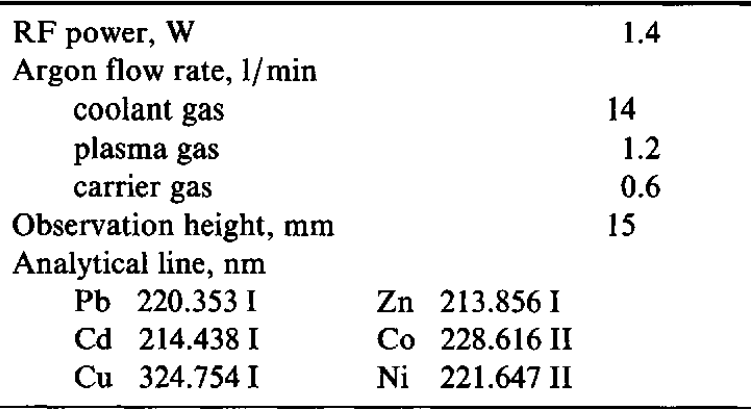

\section{Reagents}

Standard metal(II) solution: a weighed amount of metal powder (Soekawa Chemical Co., Ltd., 99.9\%) or metal(II) salt (Wako Pure Chemicals Co., Ltd.) was dissolved in $(1+1)$ nitric acid or water and then diluted to $1 \mathrm{dm}^{3}$ with water. The working solutions were prepared by diluting the stock solution.

Dithizone-TBPO solution: a weighed amount of dithizone (Wako Pure Chemicals Co., Ltd.) and TBPO (Tokyo Chemical Ind. Co., Ltd.) were dissolved in xylene to obtain $1.5 \times 10^{-3}$ and $1.0 \times 10^{-1} \mathrm{~mol} \mathrm{dm}^{-3}$ solution, respectively.

Acetate buffer solution ( $\mathrm{pH} 6.0$ ): a $0.2 \mathrm{~mol} \mathrm{dm}^{-3}$ acetic acid solution and a $0.2 \mathrm{~mol} \mathrm{dm}^{-3}$ ammonium acetate solution were mixed at an appropriate proportion.

All other chemicals used were of analytical reagent grade. Deionized water was used throughout.

\section{Preconcentration procedure}

To $300 \mathrm{~cm}^{3}$ of a water sample solution in a separatory funnel was added $3 \mathrm{~mol} \mathrm{dm}^{-3}$ ammonia. The $\mathrm{pH}$ was preliminarily adjusted to $c a .6 .0$. Then, $10 \mathrm{~cm}^{3}$ of acetate buffer solution and $3 \mathrm{~cm}^{3}$ of dithizone and TBPO solution were added, and the mixture was shaken for $30 \mathrm{~min}$. After the phases were allowed to separate, each of the two phases was applied to ICP-AES and the $\mathrm{pH}$ of the aqueous phase was measured.

\section{Results and Discussion}

The extraction of a divalent metal ion with dithizone $\left(\mathrm{H}_{2} \mathrm{dz}\right)$ proceeds according to Eq. (2):

$$
\mathrm{M}^{2+}+2 \mathrm{H}_{2} \mathrm{dz}_{\text {org }} \leftrightharpoons \mathrm{M}(\mathrm{Hdz})_{2, \mathrm{org}}+2 \mathrm{H}^{+}
$$

where the subscript org denotes the organic phase. By assuming $D=\left[\mathrm{M}(\mathrm{Hdz})_{2}\right]_{\mathrm{org}}\left[\mathrm{M}^{2+}\right]^{-1}$, Eq. (3) can be obtained:

$$
\log D=\log K_{\mathrm{ex}}+2 \log \left[\mathrm{H}_{2} \mathrm{dz}\right]_{\mathrm{org}}+2 \mathrm{pH} .
$$

Into this, Eq. (1) is introduced; the resulting equation is 
Table $2 \mathrm{pH}$ limit for preconcentration

\begin{tabular}{cccccc}
\hline $\mathrm{Cd}^{\mathrm{II}}$ & $\mathrm{Co}^{\mathrm{II}}$ & $\mathrm{Cu}^{\mathrm{II}}$ & $\mathrm{Ni}^{\mathrm{II}}$ & $\mathrm{Pb}^{\mathrm{II}}$ & $\mathrm{Zn}^{\mathrm{II}}$ \\
\hline 5.6 & 3.6 & -0.6 & 3.5 & 4.5 & 7.7 \\
\hline
\end{tabular}

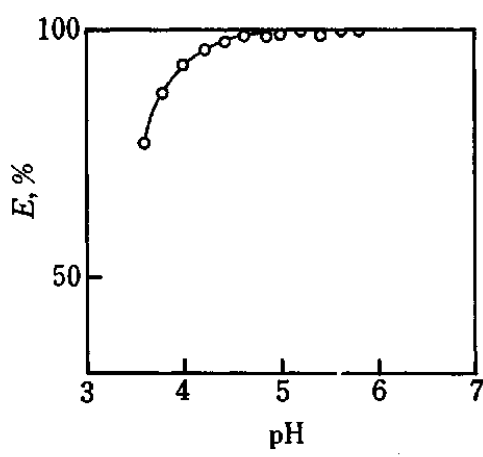

Fig. 1 Extraction curve for $\mathrm{Zn}^{\mathrm{II}}$.

as follows:

$$
\log D=S_{\mathrm{A}} S_{\mathrm{B}}+\sigma_{\mathrm{A}} \sigma_{\mathrm{B}}-2 \mathrm{p} K_{\mathrm{a}}+2 \log \left[\mathrm{H}_{2} \mathrm{dz}\right]_{\mathrm{org}}+2 \mathrm{pH}
$$

In the case that the volume ratio of the aqueous phase to the organic phase is $100, \log D$ should exceed 4 for the quantitative extraction of a metal ion, namely $99 \%$ extraction. Since $S_{\mathrm{B}}=0.46, \delta_{\mathrm{B}}=0.44, \mathrm{p} K_{\mathrm{a}}=4.47,{ }^{4}$ and $\left[\mathrm{H}_{2} \mathrm{dz}\right]_{\mathrm{org}}=1.5 \times 10^{-3} \mathrm{~mol} \mathrm{dm}^{-3}, \mathrm{pH}$ limit for preconcentration of an analyte can be calculated by using Eq. (4). The results of calculations are given in Table 2. Among the values given in Table 2 , the $\mathrm{pH}$ limit for $\mathrm{Zn}^{\mathrm{II}}$ is higher than 6.0, indicating that quantitative preconcentration of $\mathrm{Zn}^{\mathrm{II}}$ may be unsuccessful. Thus, TBPO was used for synergist to obtain quantitative extraction of $\mathrm{Zn}^{\text {II }}$ at pH 6.0. Figure 1 shows the extraction curve obtained with a mixture of dithizone and TBPO. The extraction of $\mathrm{Zn}^{\mathrm{II}}$ is quantitative at $\mathrm{pH}=6.0$. The quantitative extraction of other divalent metal ions than $\mathrm{Zn}^{\mathrm{II}}$ has already been confirmed empirically. In conclusion,
Table 3 Analytical results for the Watarase River water samples

\begin{tabular}{ccllc}
\hline & Found $^{\mathrm{a}} / \mu \mathrm{g} \mathrm{dm}^{-3}$ & D. L. & Added $/ \mu \mathrm{g}$ & Rec., \% \\
\hline $\mathrm{Cd}$ & $0.57 \pm 0.002$ & 0.054 & 0.090 & 121 \\
$\mathrm{Co}$ & $0.73 \pm 0.05$ & 0.41 & 0.30 & 127 \\
$\mathrm{Cu}$ & $85.0 \pm 0.45$ & 0.18 & 5.1 & 110 \\
$\mathrm{Ni}$ & $17.0 \pm 0.6$ & 0.57 & 3.0 & 122 \\
$\mathrm{~Pb}$ & $3.2 \pm 0.035$ & 0.87 & 0.17 & 116 \\
$\mathrm{Zn}$ & $88.0 \pm 0.07$ & 0.042 & 5.2 & 108 \\
\hline
\end{tabular}

a. Average and standard deviation of three to six determinations.

judging from the above discussion, the proposed method for preconcentration will be practically useful.

Analytical results are given in Table 3, where sample was taken from the Watarase River, and filtered through $0.45 \mu \mathrm{m}$ membrane filter. The filtrate was stored in a polyethylene bottle and analyzed as soon as possible. Results of accuracy test by the standard addition method and reproducibilities in Table 3 are satisfactory. Here, rather high recovery is attributable to the decrease in the volume of the organic phase after shaking with the aqueous phase. These facts suggest that design of preconcentration based on the HSAB rule is feasible.

\section{References}

1. Y. Itoh, H. Kawamoto and H. Akaiwa, Anal. Sci., 2, 71 (1986).

2. Y. Itoh, H. Kawamoto and H. Akaiwa, Bunseki Kagaku, 36, T119 (1987).

3. R. G. Pearson, J. Chem. Educ., 45, 581 (1968).

4. H. Kawamoto and H. Akaiwa: Chem. Lett., 1990, 1451.

(Received October 19, 1991) (Accepted January 6, 1992) 